\title{
Inhibition of Cardiomyogenesis in Embryocarcinoma Cells Induced by Long- Term High Level of Glucose
}

\author{
Wen-Juan Lia Qian-Qian Guo ${ }^{a}$ Lara Gharibeh ${ }^{b}$ Rang Xuc Sun Chen ${ }^{a} \quad K^{c}$ Sun Sun ${ }^{a}$
}

\begin{abstract}
aDepartment of Pediatric Cardiology, Xinhua hospital, Affiliated to Shanghai Jiao Tong University School of Medicine, Shanghai, China; ${ }^{b}$ Molecular Genetics and Cardiac Regeneration Laboratory, Department of Biochemistry, Microbiology and Immunology, University of Ottawa, Ottawa, Canada; 'Scientific Research Center, Xinhua hospital, Affiliated to Shanghai Jiao Tong University School of Medicine, Shanghai, China
\end{abstract}

\section{Key Words}

Differentiation • Embryocarcinoma Cells • Cardiomyocytes • PDGM • Hyperglycemia • GATA4 - Nkx2.5 • PGC-1 $\alpha$

\begin{abstract}
Background/Aims: Cardiac myocytes constitute the first differentiated cell type during mammalian heart formation with the ability to beat spontaneously and rhythmically. Hyperglycemia is a primary risk factor for cardiovascular disease in pre-gestational diabetes mellitus (PGDM). However, the impact that hyperglycemia has on cardiac progenitors or on precursors differentiation remains poorly understood. The aim of the present study is to investigate whether hyperglycemia affects cardiomyogenesis of embryocarcinoma cells. Methods: P19CL6 cells differentiation induced by $1 \%$ DMSO was evaluated under either normal glucose $(5.6 \mathrm{mmol} / \mathrm{L})$ or high level of glucose concentrations $(20 \mathrm{mmol} / \mathrm{L}$ or $40 \mathrm{mmol} / \mathrm{L})$. To investigate the effect of long-term high level of glucose on cardiomyocytes differentiation, sarcomeric $\alpha$-actinin, peroxisome proliferator-activated receptor coactivator-1 (PGC-1 $\alpha$ ), transcription factor GATA4 and Nkx2.5 were assessed by qRT-PCR analysis, western blot and immunofluorescence. Results: We observed that long-term high level of glucose markedly reduced P19CL6 cells differentiation into cardiomyocytes. The change in PGC-1 $\alpha$ expression was consistent with changes in cardiac muscle myosin expression after exposure to $20 \mathrm{mmol} / \mathrm{L}$ or $40 \mathrm{mmol} / \mathrm{L}$ of glucose. On the other hand, the high level of glucose concentration profoundly decreased both GATA4 and Nkx2-5 expressions from day 6 to day 12 after differentiation, which was induced by $1 \%$ DMSO. Conclusion: Our results elucidate that the effect resulting from the long-term exposure of cardiac progenitors to high level of glucose is associated with decreased expression of GATA4 and Nkx2.5, providing a novel mechanism by which high glucose is able to affect cell differentiation.




\section{Cellular Physiology Cell Physiol Biochem 2016;38:2041-2052 \\ \begin{tabular}{l|l} 
and Biochemistry & DOI: 10.1159/000445563 2016 The Author(s). Published by S. Karger AG, Basel \\
Published online: May 11, 2016 & $\begin{array}{l}\text { (c) } \\
\text { www.karger.com/cpb }\end{array}$
\end{tabular} \\ Li et al: Development, Cardiomyogenesis, Differentiation}

\section{Introduction}

Diabetes mellitus is a common complication in pregnancy, and pre-gestational diabetes mellitus (PGDM) is one of the leading risk factors for birth defects. PGDM is associated with a wide spectrum of anomalies affecting many organs during development. In an in vivo rat embryo model, approximately $50 \%$ of the rat embryos which were exposed to $600 \mathrm{mg} / \mathrm{dl}$ of glucose post-implantation for 2 hours or longer, during early stage of organogenesis, were malformed [1]. Among the numerous congenital malformations with PGDM, cardiovascular defects are the most frequent $[2,3]$. Studies performed in animal models demonstrated that offspring of diabetic mice show increased myocardial collagen deposition and myocardial hyperplasia in late gestation $[4,5]$. To date, hyperglycemia is considered to be a primary teratogen affecting organ development. Some retrospective reviews of diabetic pregnancies in human reported that poor glycemic control in early pregnancy is associated with increased risk of heart defects in offspring; the incidence of CHD in PGDM patients with a level of hemoglobin A1c (HbA1c) above 8.5\% was almost three times higher than the incidence observed in patient with HbA1c levels lower than 8.5\% [6, 7]. Furthermore, fetal glucose concentration depends on fetal glucose uptake. This uptake relates to the maternal-fetal glucose concentration gradient and glucose-stimulated insulin secretion. Constant hyperglycemia is usually responsible for downregulating insulin secretion whereas pulsatile hyperglycemia in fetus enhances it [8]. Thus, hyperglycemia has more impact on the fetus than on its mother. In fact, many pregnant women with PGDM are unaware of the increased risk of cardiovascular defects that hyperglycemia has on their unborn child, especially during early gestational phase; The reason behind that relate to the late diagnoses of gestational diabetes, which usually occurs after heart formation is completed. Although high maternal glucose concentration in late gestation is found to be associated with heart defects, the impact that long-term hyperglycemia has on cardiac progenitors or on precursor differentiation still needs to be elucidated.

During cardiomyogenesis, a transition from glycolytic metabolism to mitochondrial oxidative phosphorylation is required in order to meet the high energy levels required by the cardiomyocytes. Fatty acid oxidation is considered the major source of mitochondrial energy generation in mature cardiomyocytes $[9,10]$. Over the last few years, Peroxisome proliferator-activated receptor g coactivator-1 (PGC-1 $\alpha$ ) was found to be highly expressed in tremendous energy consumption organs such as the brain, heart and skeletal muscles. It has been also shown to play critical regulatory roles in stimulating mitochondrial biogenesis and modulating mitochondrial functions in many cell types. Overexpression of PGC-1 $\alpha$ in rat neonatal cardiomyocytes was reported to induce an increase in oxygen consumption. On the other hand, a decrease in the expression of Fatty acid oxidation (FAO) gene and ATP synthesis genes was observed in mice deficient in PGC-1 $\alpha[11,12]$. GATA4, a member of the GATA family of transcription factors (TF), is a key cardiogenic regulator of heart development. GATA4 is found to be expressed in cardiac progenitors and its expression usually persists till later stages of embryogenesis. GATA-4 has been shown to regulate the expression of many other cardiac genes during cardiomyogenesis including A- and B-type natriuretic peptides as well as alpha myosin heavy chain (aMHC). Inhibition of GATA-4 expression has been shown to block in vitro cardiac muscle differentiation [13]. Nkx-2.5 homeobox gene, another TF expressed in cardiac progenitors, plays an important role in the differentiation of the myocardial lineage $[14,15]$. In mice, loss of $N k x 2.5$ revealed an essential role in the establishment of the ventricular gene expression program [16]. Unlike GATA-4, Nkx2.5 does not appear to be directly required for myogenic genes regulation but is able to exert its role in cardiomyogenesis via combinatorial interaction with other cardiac TF $[17,18]$.

Embryonic stem cells (ES) or induced pluripotent stem cells (iPS) are considered as useful in vitro cardiomyogenesis models for their ability to self-renew and remain pluripotent [19-21]. However, the effects of different glucose concentration on embryoid body (EB) formation, derived from mouse ES cells or iPS cells, differed from human ES cells. Glucose concentration is found to affect the propensity for cell differentiation after 
formation of the EB $[22,23]$. P19CL6 cells were established from colonel derivatives of P19 cells by Habara-Ohkubo [24]. It has been reported that P19CL6 cells differ from P19 cells in their pluripotency state and have properties similar to cardiac precursors [25, 26]. On the other hand, P19CL6 cells remain important for investigating the molecular mechanism of cardiomyogenesis as authentic cardiomyocytes precursors; these cells can be successfully and effectively differentiated into beating cardiomyocytes using 1\% DMSO over a period of 10 days, without EB formation. Expression of many cardiac differentiation markers as well as cardiac myosin occurs during the differentiation period of these cells, whereas no expression of skeletal muscle-specific markers, such as MyoD and myogenin is present [27, 28]. Therefore, P19CL6 cells have been used as an in vitro embryocarcinoma cells model to examine the differentiation mechanisms of cardiac precursors.

In this paper, we investigated whether P19CL6 cells can successfully differentiate into contractile cardiomyocytes under long-term high level of glucose concentration. We report here that high levels of glucose are able to inhibit P19CL6 cells differentiation into cardiomyocytes by downregulation of GATA4 and Nkx2-5 expressions and disturbing the switch to mitochondrial oxidative metabolism during differentiation. The result has provided important clues regarding the effect that hyperglycemia has on cardiac progenitors or precursors.

\section{Materials and Methods}

\section{Cell culture and differentiation}

P19CL6 cells were kindly provided by Prof.Yunzeng Zou (Institutes of Biomedical Sciences, Fudan University, Shanghai, China). Cells were cultured in $\alpha$-MEM medium containing $5.6 \mathrm{mmol} / \mathrm{L}$ glucose which is normally maintained and differentiated into cardiomyocytes of P19CL6 cells; the medium also supplemented with penicillin $(100 \mathrm{U} / \mathrm{ml})$, streptomycin $(100 \mu \mathrm{g} / \mathrm{ml}), 10 \%$ fetal bovine serum, and were maintained in a $5 \% \mathrm{CO}_{2}$ atmosphere at 37 degree. The cells were reseeded every 3 days. Cells were used for experimental differentiation between 5-10 passages. To induce differentiation, P19CL6 cells were seeded at $1.8 \times 10^{5}$ cells in 6 -well plates or $1.0 \times 10^{4}$ cells in 4 well glass slide, followed by incubation with $1 \%$ DMSO added in growth medium over 12 days, Cells cultures incubated in high glucose were also incubated with $20 \mathrm{mmol} / \mathrm{L}$ or $40 \mathrm{mmol} / \mathrm{L} \mathrm{D}$-glucose, respectively. The medium was changed every day.

\section{Immunofluorescence}

For sarcomeric $\alpha$-actinin staining, cells were harvested at day 12 after induction, while for GATA4 and Nkx2-5 staining, cells were harvested at day 9 after induction. After fixation with $4 \%$ paraformaldehyde at room temperature for $15 \mathrm{~min}$, followed by permeatigation with $0.3 \%$ TritonX-100 for $15 \mathrm{~min}$ and blocked with $5 \%$ BSA for $60 \mathrm{~min}$, respectively, cells were then incubated with primary antibody(1:800 monoclonal anti- sarcomeric $\alpha$-actinin (SAB3300072, Sigma-Aldrich), 1:500 polyclonal anti-GATA4 (sc-1237, Sant Cruz) or 1:800 polyclonal anti-NKX2-5(ab35842, Abcam)) at 4 degree overnight, and followed by incubation with Alexa Fluor ${ }^{\circledR} 594$ or 488 conjugate secondary antibody (Life technologies) at room temperature in dark for 45 min. DAPI (ab104139, Abcam) was used for nuclear stain. The images were acquired using fluorescence microscopy at 200X or 400X magnification using Image pro Plus software.

\section{Quantitative real-time PCR}

Total RNA was extracted from cells at indicated time pints by TRIzol. RT-PCR was performed as previously described. cDNAs were generated from 1 ug of total RNA using the Omniscript RT Kit (QIAGEN, Inc.) QPCR was carried out with the Quantitect SYBR Green PCR kit (QIAGEN) in a MX4000 real-time PCR machine. Relative gene expression levels were calculated using the DDCt method, with the TBP as normalizing gene. The primers used were as followed: GATA4: 5'- CAC AAG ATG AAC GGC ATC AAC -3 ' and 5'- AGG CAT TAC ATA CAG GCT CAC-3'; Nkx2-5: 5'- GTG GGT CTC AAT GCC TATGG-3' and 5'- TCA TCG CCC TTC TCC TAAAG-3'; BNP: 5'- CAG CTC TTG AAG GAC CAAGG-3' and 5'- AGA GAC CCA GGC AGA GTCAG-3'; $\alpha$-MHC: 5'- TCA AGG AGC TCA CCT ACCAG-3' and 5'- GTT GCA AAG GCT CCA GGTC-3'; $\beta$-MHC: 5'- AAG CTG CAG TTG AAG GTG AAGG-3' and 5'- AGC TTG TTG ACC TGG GACTC-3'; PGC-1 $\alpha$ : 5'- AAG AGC GCC GTG TGA 
TTTAC-3' and 5'- AGC AGG GTC AAA ATC GTCTG-3'; MCAD: 5' - ACC CTC GTG TAA CTA AGCTC-3' and 5'- AAT GCT GCT ATG TCA CAGTC-3'; MyoD; 5'- CCC CGG CGG CAG AAT GGC TACG-3' and 5'- GGT CTG GGT TCC CTG TTC TGTGT-3'.

\section{Western Blot analysis}

Cells were harvested in presence or absence of high glucose at different time points. The protein was extracted as previously described. A total of $20 \mathrm{ug}$ of extracts was subjected to immunoblotted. The antibodies were used as followed: Rabbit polyclonal anti-GATA4 1:1000 (sc-1237, Sant Cruz), Rabbit polyclonal antiNkx2-5 1:1000 (ab35842, Abcam)), Rabbit polyclonal anti- PGC-1 $\alpha$ 1:1000, mouse monoclonal sarcomeric $\alpha$-actinin 1:1500 (SAB3300072, Sigma-Aldrich) and peroxidase conjugated secondary antibody (Jackon).

\footnotetext{
Statistical analysis

Data are showed as means \pm SEM. Two-way analysis of variance was used to compare between groups. P- Value $<0.05$ was considered as an index of statistical significance.
}

\section{Results}

DMSO-induced P19CL6 cells differentiation into cardiomyocytes

To investigate the effect that long-term high levels of glucose concentration has on cardiomyocytes differentiation; a stable in vitro model of induction of P19CL6 cells differentiation into cardiomyocytes was used. Following exposure of the cells to $1 \%$ DMSO, differentiation of these cells was induced: the cells were forming patches and contracting over a period of 12 days as presented by spontaneous and rhythmic beating, comparable to the state of differentiated cardiomyocytes. To further verify whether these differentiated cells were actually cardiomyocytes, immunofluorescence at day 12 after induction was conducted to check the expression of sarcomeric $\alpha$-actinin protein (differentiation marker, Green) (Fig. $1 \mathrm{~A}-\mathrm{F}$ ). In the presence of $1 \%$ DMSO, sarcomeric $\alpha$-actinin was highly expressed in these cells indicative of a cardiac differentiated phenotype. 5-6 random fields per coverslip were photographed and counted out autofluorescence regions, in the presence of $1 \%$ DMSO, the area of sarcomeric $\alpha$-actinin staining could reached to $(15.44 \% \pm 4.19 \%)$. The expression of cardiac specific TF and genes was also examined by qRT-PCR analysis and western blot during P19CL6 differentiation. Increased expression of GATA4 was detected at day 3 which increased exponentially till day 9 after induction (Fig. 1G), whereas Nkx2-5 and BNP expressions were detected from day 9 to day 12 after induction (Fig. 1H, I). Both cardiac myosin $\alpha$-MHC and $\beta$-MHC expressions peaked at day 9 (Fig. 1J-K). These results were recapitulated in Western blot analysis where increasing protein expressions of $\alpha$-actinin and NKX2.5 were shown, although slight difference of GATA4 expression pattern was observed (Fig. 1L, M). however, we did not detect skeleton muscle markers expression increased during differentiation (Fig. $1 \mathrm{~N})$. In contrast to cardiomyocytes precursors, establishment of a mitochondrial oxidative metabolism is required to meet the energy demands in functional cardiomyocytes. The expression of FAO genes, including medium-chain acyl CoA dehydrogenases (MCAD) and PGC- $1 \alpha$ are considered as markers of functional cardiomycocytes. The expression of these genes was detected by qRT-PCR at late stages after differentiation induction and results showed a high expression of MCAD and PGC-1 $\alpha$ mRNA at day 9 and day12 (Fig. 1 O,P). Together, these data prove that P19CL6 cells successfully differentiated into cardiomyocytes after exposure to $1 \%$ DMSO.

Long-term high glucose inhibits P19CL6 cells differentiation into cardiomyocytes

To elucidate the effect of long-term high concentration of glucose on P19CL6 cells differentiation, immunofluorescence of sarcomeric $\alpha$-actinin was carried out on P19CL6 differentiated cells treated with $5.6 \mathrm{mmol} / \mathrm{L}$ (normal concentration), $20 \mathrm{mmol} / \mathrm{L}$ and 40 $\mathrm{mmol} / \mathrm{L}$ D-glucose at day 12 after DMSO-induction (Fig. 2A). We measured ratios of cardiac $\alpha$-actin-positive cell areas to total areas of microscopic fields, the positive cell areas in high 


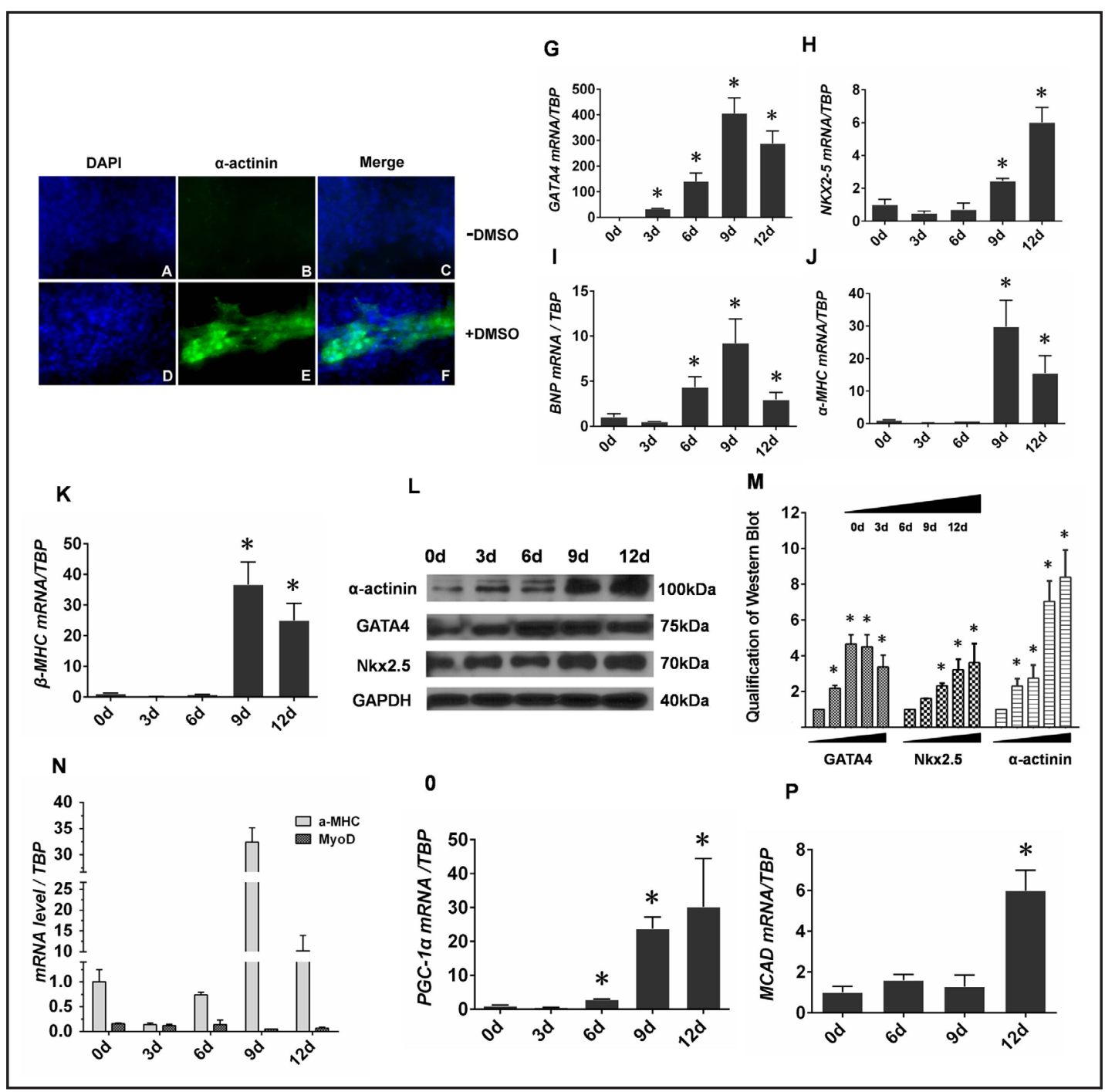

Fig. 1. P19CL6 cells differentiation into cardiomyocytes induced by $1 \%$ DMSO. (A-C) Immunofluorescence of $\alpha$-cardiac actinin on P19CL6 cells treated without 1\% DMSO at day 12; (D-F) Immunofluorescence of sarcomeric $\alpha$-actinin on P19CL6 cells treated with 1\% DMSO at day 12, note the positive cells (green). (G-K) Gene expression profile by qRT-PCR analysis using RNA extracted from P19CL6 cells at indicated times during P19CL6 cells differentiation, showed increased expression of TF GATA4 detected at day 3, which increased sharply after that, while Nkx2-5 and BNP increased 6 days after the induction. Expressions of cardiac myosin $\alpha$-MHC and $\beta$-MHC were detected at day 9. (L-M) Western blot demonstrating the expression of GATA4, Nkx2-5, sarcomeric $\alpha$-actinin, note the increase in the protein levels of GATA4, Nkx2-5 and sarcomeric $\alpha$-actinin which were consistent with the qRT-PCR analysis. (N) Expression of skeleton muscle markers during P19CL6 cells differentiation induced by 1\% DMSO as compared to $\alpha$-MHC. (O-P) increased expression of fatty acid oxidation (FAO) genes, medium-chain acyl CoA dehydrogenases (MCAD) and peroxisome proliferator-activated receptor- $\gamma$ co-activator $1 \alpha$ (PGC- $1 \alpha)$, during induction of P19CL6 differentiation $\left({ }^{*} \mathrm{p}<0.05\right.$, Statistical significant vs day 0$)$.

level of glucose treatment group were reduced to $(7.10 \% \pm 2.57 \%)$ and $(3.65 \% \pm 0.83 \%)$, respectively. Results showed a reduction in the expression of sarcomeric $\alpha$-actinin after increasing the doses of glucose in the medium. $20 \mathrm{mmol} / \mathrm{L}$ D-glucose treatment resulted in downregulation of the expression of cardiac myosin genes ( $\alpha-\mathrm{MHC}$ and $\beta-\mathrm{MHC}$ ) during differentiation process (Fig. 2B-C), whereas exposure to $40 \mathrm{mmol} / \mathrm{L}$ D-glucose almost diminished its expression as shown by immunofluorescence and qRT-PCR. These data 


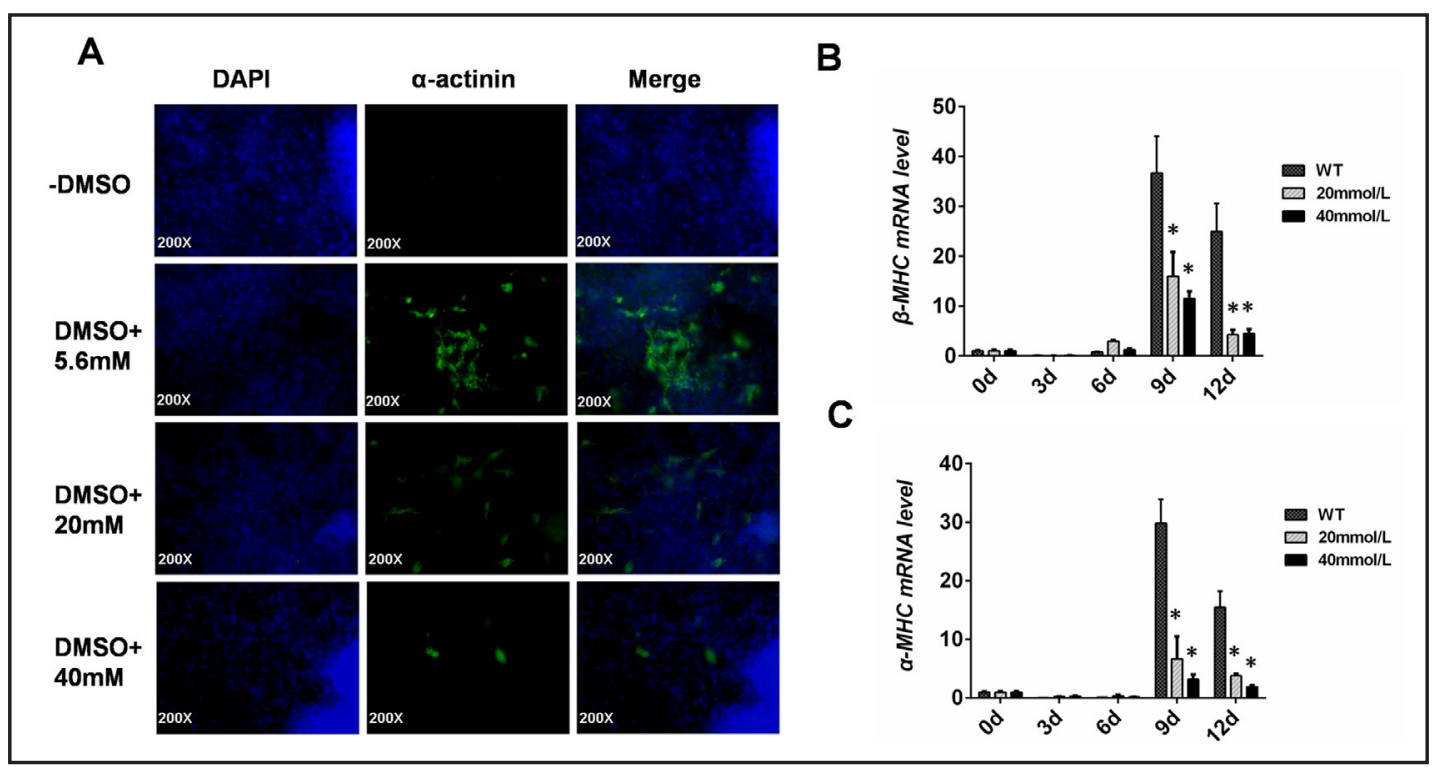

Fig. 2. High glucose inhibited P19CL6 cells differentiation into cardiomyocytes. (A) Immunofluorescence of sarcomeric $\alpha$-actinin (green) on differentiated P19CL6 cells with different concentration of D-glucose at day 12 after induction, less positive cells were observed in $20 \mathrm{mmol} / \mathrm{L} \mathrm{or} 40 \mathrm{mmol} / \mathrm{L}$ glucose treated cells in comparison to normal concentration ( $5.6 \mathrm{mmol} / \mathrm{L}$ ). (B-C) qRT-PCR analysis using RNA from differentiated P19CL6 cells demonstrating significant changes in the m RNA levels of $\alpha$-MHC and $\beta$-MHC when P19CL6 cells were treated with $20 \mathrm{mmol} / \mathrm{L}$ or $40 \mathrm{mmol} / \mathrm{L}$ glucose. $\left({ }^{*} \mathrm{p}<0.05\right.$, Statistical significant vs the WT of the same day).

indicated that long-term exposure to high level of glucose has a drastic effect on P19CL6 cells by inhibiting their differentiation.

Long-term high glucose is associated with decreased PGC-1 $\alpha$ expression during P19CL6 differentiation

To further investigate the mechanisms underlying the effect of long-term high glucose concentration on P19CL6 differentiation, we examined the levels of mitochondrial oxidative metabolism protein PGC- $1 \alpha$. Compared to controls, PGC- $1 \alpha$ protein level was profoundly reduced in differentiated P19CL6 cells treated with $20 \mathrm{mmol} / \mathrm{L}$ or $40 \mathrm{mmol} / \mathrm{L} \mathrm{D}$-glucose at day 12 after induction (Fig. 3A-B). Unexpectedly, exposure to $20 \mathrm{mmol} / \mathrm{L} \mathrm{D}$-glucose resulted in a temporary increase in mRNA level of PGC- $1 \alpha$ at day 9 followed by a decrease in its expression at day 12 after induction. However, exposure to $40 \mathrm{mmol} / \mathrm{L} \mathrm{D}$-glucose induced a lower expression of PGC- $1 \alpha$ at day 6, day 9 and day 12 after induction (Fig. 3C). Moreover, mRNA level of FAO genes such as MCAD also decreased in differentiated cells treated with 20 $\mathrm{mmol} / \mathrm{L}$ D-glucose or $40 \mathrm{mmol} / \mathrm{L} \mathrm{D}$-glucose at day 12 after induction (Fig. 3D). These results suggest that long-term exposure to high glucose decreases expression of genes involved in the regulation of mitochondrial biogenesis and function during P19CL6 cells differentiation, which might underlie the defects associated with the switch to mitochondrial oxidative metabolism in differentiated cells.

Long-term high glucose decreased GATA4 and Nkx2.5 expression during P19CL6 differentiation

To further investigate cardiac gene expression profile following high glucose concentration exposure, qRT-PCR and Western blot analysis were performed to detect the expression of GATA4 and Nkx2-5 transcription factors. The data revealed that treatment with $20 \mathrm{mmol} / \mathrm{L}$ D-glucose decreases the expression of both GATA4 and Nkx2-5 throughout day 6, 9 and 12 after induction when compared to cells treated with $5.6 \mathrm{mmol} / \mathrm{L}$ of glucose.

\section{KARGER}




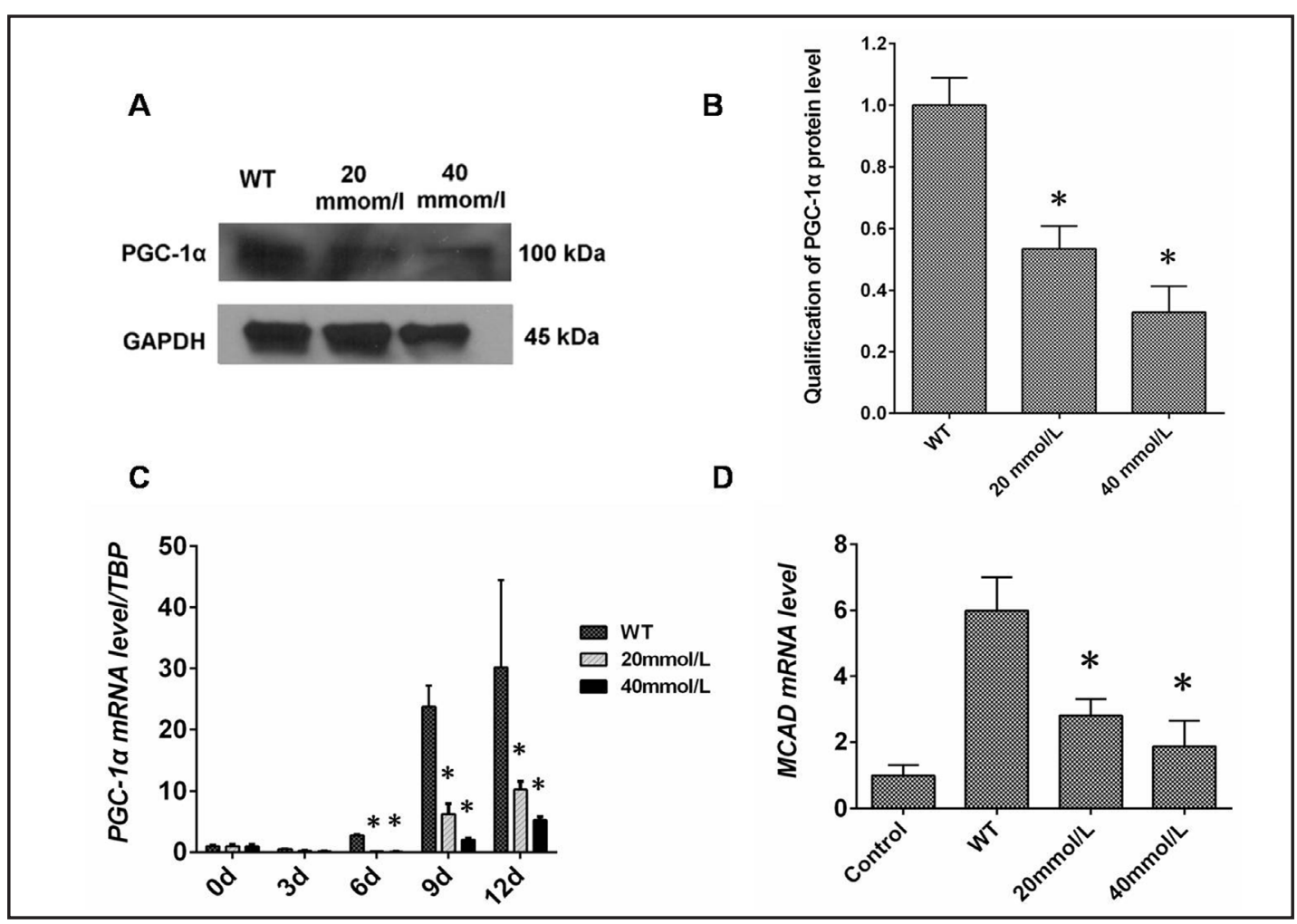

Fig. 3. High glucose decreased PGC-1 $\alpha$ and MCAD genes expression during P19CL6 cells differentiation. (A-B) Western blot showing significant decrease in PGC-1 $\alpha$ expression at day 12 after treatment with high D-glucose concentration following induction of differnetiation. (C) qRT-PCR analysis demonstrated significant changes in the m RNA levels of PGC-1 $\alpha$ during P19CL6 cells differentiation. (D) qRT-PCR analysis at day 12 demonstrated significant changes in MCAD after cells where treated with high D-glucose concentration after induction. $\left({ }^{*} \mathrm{p}<0.05\right.$, Statistical significant vs the WT of the same day).

Exposure of the cells to $40 \mathrm{mmol} / \mathrm{L}$ D-glucose further reduces their expression (Fig. 4A-D). As show in Fig. 4E, immunofluorescence staining of GATA4 and Nkx2-5 performed at day 9 after induction also indicated lower detection of GATA4 and Nkx2-5 positive cells in P19CL6 cells treated with $20 \mathrm{mmol} / \mathrm{L}$ or $40 \mathrm{mmol} / \mathrm{L}$ D-glucose, respectively, when compared to cells treated with $5.6 \mathrm{mmol} / \mathrm{L}$ of glucose. The findings indicate that exposure to high level of glucose for a long term inhibits P19CL6 cells differentiation into cardiomyocytes by decreasing GATA4 and Nkx2-5 expressions.

\section{Discussion}

PGDM is considered as a rising problem with increasing impact on embryonic development especially that defects in the cardiovascular system development are the main defects associated with PGDM. Spontaneously beating cardiomyocyte are the first type of differentiated cells to appear during mammalian heart formation [29]. Throughout heart formation, cardiomyocytes proliferate and organize themselves to give rise to the mature four-chambered heart. Up until recently, it has been known that hyperglycemia is a primary factor affecting heart development. However, little is known about the impact of hyperglycemia on cardiac progenitors or precursors. Here we show that long-term high glucose levels inhibit cardiac differentiation of P19CL6 cells. These results, revealing that cardiac differentiation is altered in response to high glucose, provide important clues regarding the effect of hyperglycemia on cardiac progenitors or precursors. 


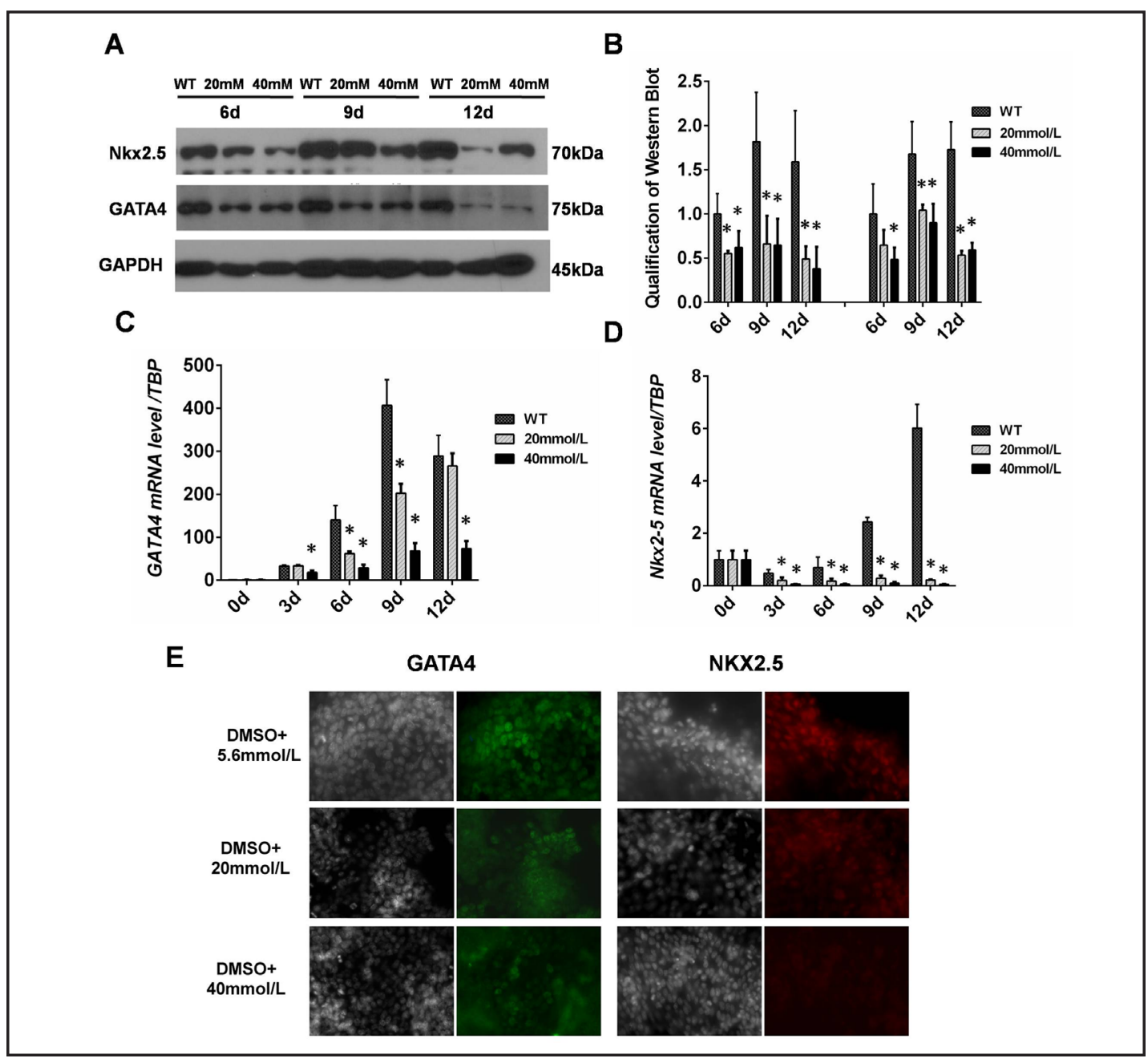

Fig. 4. High glucose decreased expression of GATA4 and Nkx2-5 expression during P19CL6 cells differentiation. (A-B) Western blot showing small protein amounts of GATA4 and Nkx2-5 in cells treated with high glucose at day 6, day 9 and day 12. (C-D) qRT-PCR analysis demonstrating a significant decrease in mRNA level of GATA4 and Nkx2-5, which were consistence with imunofluorescence and western blot findings. (E) Immunofluorescence of GATA4 and Nkx2-5 on differentiated P19CL6 cells with different concentration of D-glucose at day 9, showing less GATA4 (green) and Nkx2-5 (red) positive cells detected in cells treated with $20 \mathrm{mmol} / \mathrm{L}$ and $40 \mathrm{mmol} / \mathrm{L}$ glucose in comparison to the normal concentration (5.6 mmol/L) $\left({ }^{*} \mathrm{p}<0.05\right.$, Statistical significant vs the WT of the same day).

During four-chamber formation, the number of mitochondria increases along with important mitochondrial proteins in order to meet the increases in ATP consumption due to the elevation of embryonic heart output $[9,10]$. Several lines of evidence indicated that PGC- $1 \alpha$ is a key regulator of mitochondrial functional capacity in the heart, and is involved in cardiomyocyte differentiation of murine embryonic stem cells in vitro[12, 30-32]. VegaNaredo et al. reported that P19 cells were able to increase the intrinsic mitochondrial membrane potential $(\Delta \psi \mathrm{m})$ and respiration, reduce their proliferation and differentiation, when mitochondrial metabolism was forced using OXPHOS medium [33]. In this study, and under physiological glucose concentration, the trend of PGC- $1 \alpha$ expression changed in accordance with changes in cardiac muscle myosin expression, suggesting that successful transition of embryonic stem cells to functional cardiomyocytes comes with an increase in mitochondrial function in differentiated cells. Gao et al. using differentiated 3T3-L1 
adipocytes model showed that high level of glucose are able to induce mitochondrial dysfunction by inducing downregulation of PGC-1 $\alpha$ [34]; On the other hand, our study showed that PGC-1 $\alpha$ expression was sensitive to high glucose concentrations during P19CL6 cell differentiation, with alteration of genes involved in mediating fatty acid oxidation. Thus deficiency in the switch to mitochondrial oxidative metabolism is maybe associated with decreased expression of PGC- $1 \alpha$ that occurs under high level of glucose during P19CL6 cells differentiation. Recently, several signaling pathways have been implicated in the regulation of PGC- $1 \alpha$ promoter activation and expression in response to various stimuli [35, 36]. Irrcher et al identified three GATA sequence in PGC-1 $\alpha$ promoter by cloning the proximal $2-\mathrm{kb}$ human PGC-1 $\alpha$ promoter, suggesting that GATA family of TF could regulate the activation of this promoter. In fact, GATA4 overexpression alone increased the activation of hPGC-1 $\alpha$ promoter in C2C12 cells [37].

Transcription factor GATA4, expressed in early cardiac progenitor cells prior to cardiomyogenesis and then throughout adulthood, has a key role in cardiomyogenesis. The impact that hyperglycemia has on GATA4 expression was previously reported: the study elucidated that high glucose is able to induce GATA4 depletion in cardiomyocytes by increasing the degradation of GATA4 protein or by affecting the phosphorylation of GATA4, which is induced by MEK/ERK signaling [38, 39]. Interestingly, we found in our study using qRT-PCR analysis, Western blot and immunofluorescence assays that the decrease in GATA4 expression happens under high level of glucose concentration, suggesting that GATA4 is sensitive to glucose concentration stimulation both in cardiac progenitors and mature cardiomyocytes. Furthermore, exposure to high levels of glucose concentration showed trend changes in GATA4 expression similar to what was seen with cardiac myosin expression, suggesting that GATA4 is the first cardiac TF to be induced during P19CL6 cells differentiation; our findings are consistent with previously reported studies which show that absence of GATA4 in P19 cells or ES cells render them unable to form beating cardiomyocytes [40, 41].

Nkx2-5 is another important TF expressed throughout cardiac development, with high levels in embryonic differentiated cardiomyocytes [15]. In vitro Nkx2.5 gain and loss-offunction studies indicated that Nkx2.5 function appears to be essential for cardiomyogenesis in P19 cells by activation of myocyte enhancer factor 2C (MEF2C) [18, 42]. These results are in accordance with our findings showing a decrease in the expression of Nkx2.5 and cardiac myosin gene during the process of differentiation, after treatment with high levels of glucose. However, ectopic expression of Nkx2.5 in frog and zebrafish led to the recruitment of additional myocytes into the heart, but was not sufficient to initiate cardiac cell differentiation into functional cardiomyocytes [14, 43], suggesting that Nkx2.5 is able to determine the cardiac cell fate via acting in cooperation with other TF. Since the expression pattern of GATA4 and Nkx2.5 factors is largely overlapping in cardiomyogenesis, it is possible that these two factors might be regulating each other's expression or are physically interacting. In fact, GATA4 binding sites are indeed present in the mouse Nkx2.5 promoter and inactivation of Nkx2.5 did not affect expression of GATA-4 [44-47]. These results suggest that GATA4 may function upstream of Nkx2.5, confirming the results reported in this study: expression of GATA4 precedes Nkx2.5 expression. Furthermore, it is well-known that Nkx2.5 and GATA4 are capable of co-activating early cardiac gene promoters including cardiac actin and ANF, through binding to their adjacent DNA binding sites [48-50].These findings could potentially explain why a decrease in expression of cardiac myosin was detected along with the decrease in GATA4 expression after exposure to high glucose concentration. Thereby, inhibition of cardiogenesis in P19CL6 cells, exposed to high levels of glucose, is associated with decreases in GATA4 and Nkx2.5 expression, which eventually results in the downregulation of cardiac myosin and other TF such as PGC- $1 \alpha$.

In conclusion, high level of glucose is able to inhibit P19CL6 cell differentiation via targeting the expression of genes involved in mitochondrial oxidative metabolism; the mechanism is mediated via the regulation of GATA4 and Nkx2.5 expressions. These findings represent a novel mechanism by which glucose concentration affects cell differentiation and shed more light on the effect of hyperglycemia on heart development. 


\section{Cellular Physiology Cell Physiol Biochem 2016;38:2041-2052 \begin{tabular}{l|l} 
and Biochemistry & DOI: 10.1159/000445563 \\
Published online: May 11, 2016 & $\begin{array}{l}\text { (c) } 2016 \text { The Author(s). Published by S. Karger AG, Basel } \\
\text { www.karger.com/cpb }\end{array}$
\end{tabular}}

Li et al.: Development, Cardiomyogenesis, Differentiation

\section{Acknowledgements}

This work was supported by National Basic Research Program of China, No. 81270233; Science and Technology Commission of Shanghai Municipality, China, No. 13JC1401705 and the Leading Academic Discipline Project of Shanghai Education Committee, China, No. 15ZZ055. The authors gratefully thank Dr. Yunzeng Zou, Fudan University Shanghai, for P19CL6 cells.

\section{Disclosure Statement}

The authors declare that they have no competing interests.

\section{References}

1 Reece EA, Wiznitzer A, Homko CJ, Hagay Z, Wu YK: Synchronization of the factors critical for diabetic teratogenesis: an in vitro model. Am J Obstet Gynecol 1996;174:1284-1288.

2 Gabbay-Benziv R, Reece EA, Wang F, Yang P: Birth defects in pregestational diabetes: Defect range, glycemic threshold and pathogenesis. World J Diabetes 2015;6:481-488.

3 Correa A, Gilboa SM, Besser LM, Botto LD, Moore CA, Hobbs CA, Cleves MA, Riehle-Colarusso TJ, Waller DK, Reece EA: Diabetes mellitus and birth defects. Am J Obstet Gynecol 2008;199:237. e231-239.

4 Dowling D, Corrigan N, Horgan S, Watson CJ, Baugh J, Downey P, McAuliffe FM: Cardiomyopathy in offspring of pregestational diabetic mouse pregnancy. J Diabetes Res 2014;2014:624939.

5 Corrigan N, Treacy A, Brazil DP, McAuliffe FM: Cardiomyopathy and diastolic dysfunction in the embryo and neonate of a type 1 diabetic mouse model. Reprod Sci 2013;20:781-790.

6 Starikov R, Bohrer J, Goh W, Kuwahara M, Chien EK, Lopes V, Coustan D: Hemoglobin A1c in pregestational diabetic gravidas and the risk of congenital heart disease in the fetus. Pediatr Cardiol 2013;34:1716-1722.

7 Ullmo S, Vial Y, Di Bernardo S, Roth-Kleiner M, Mivelaz Y, Sekarski N, Ruiz J, Meijboom EJ: Pathologic ventricular hypertrophy in the offspring of diabetic mothers: a retrospective study. Eur Heart J 2007;28:1319-1325.

8 Hay WW Jr: Placental-fetal glucose exchange and fetal glucose metabolism. Trans Am Clin Climatol Assoc 2006;117:321-339; discussion 339-340.

9 Chung S, Dzeja PP, Faustino RS, Perez-Terzic C, Behfar A, Terzic A: Mitochondrial oxidative metabolism is required for the cardiac differentiation of stem cells. Nat Clin Pract Cardiovasc Med 2007;4:S60-67.

10 Lopaschuk GD, Jaswal JS: Energy metabolic phenotype of the cardiomyocyte during development, differentiation, and postnatal maturation. J Cardiovasc Pharmacol 2010;56:130-140.

11 Arany Z, He H, Lin J, Hoyer K, Handschin C, Toka O, Ahmad F, Matsui T, Chin S, Wu PH, Rybkin II, Shelton JM, Manieri M, Cinti S, Schoen FJ, Bassel-Duby R, Rosenzweig A, Ingwall JS, Spiegelman BM: Transcriptional coactivator PGC-1 alpha controls the energy state and contractile function of cardiac muscle. Cell Metab 2005;1:259-271.

12 Lehman JJ, Barger PM, Kovacs A, Saffitz JE, Medeiros DM, Kelly DP: Peroxisome proliferator-activated receptor gamma coactivator-1 promotes cardiac mitochondrial biogenesis. J Clin Invest 2000;106:847-856.

13 Grepin C, Robitaille L, Antakly T, Nemer M: Inhibition of transcription factor GATA-4 expression blocks in vitro cardiac muscle differentiation. Mol Cell Biol 1995;15:4095-4102.

14 Chen JN, Fishman MC: Zebrafish tinman homolog demarcates the heart field and initiates myocardial differentiation. Development 1996;122:3809-3816.

15 Lints TJ, Parsons LM, Hartley L, Lyons I, Harvey RP: Nkx-2.5: a novel murine homeobox gene expressed in early heart progenitor cells and their myogenic descendants. Development 1993;119:419-431.

16 Lyons I, Parsons LM, Hartley L, Li R, Andrews JE, Robb L, Harvey RP: Myogenic and morphogenetic defects in the heart tubes of murine embryos lacking the homeo box gene Nkx2-5. Genes Dev 1995;9:1654-1666.

17 Harvey RP: NK-2 homeobox genes and heart development. Dev Biol 1996;178:203-216. 
18 Skerjanc IS, Petropoulos H, Ridgeway AG, Wilton S: Myocyte enhancer factor 2C and Nkx2-5 up-regulate each other's expression and initiate cardiomyogenesis in P19 cells. J Biol Chem 1998;273:34904-34910.

19 Ivanyuk D, Budash G, Zheng Y, Gaspar JA, Chaudhari U, Fatima A, Bahmanpour S, Grin VK, Popandopulo AG, Sachinidis A, Hescheler J, Saric T: Ascorbic Acid-Induced Cardiac Differentiation of Murine Pluripotent Stem Cells: Transcriptional Profiling and Effect of a Small Molecule Synergist of Wnt/beta-Catenin Signaling Pathway. Cell Physiol Biochem 2015;36:810-830.

20 Semmler J, Lehmann M, Pfannkuche K, Reppel M, Hescheler J, Nguemo F: Functional expression and regulation of hyperpolarization-activated cyclic nucleotide-gated channels (HCN) in mouse iPS cell-derived cardiomyocytes after UTF1 -neo selection. Cell Physiol Biochem 2014;34:1199-1215.

21 Xu R, Srinivasan SP, Sureshkumar P, Nembo EN, Schafer C, Semmler J, Matzkies M, Albrechtsen M, Hescheler J, Nguemo F: Effects of synthetic neural adhesion molecule mimetic peptides and related proteins on the cardiomyogenic differentiation of mouse embryonic stem cells. Cell Physiol Biochem 2015;35:2437-2450.

22 Khoo ML, McQuade LR, Smith MS, Lees JG, Sidhu KS, Tuch BE: Growth and differentiation of embryoid bodies derived from human embryonic stem cells: effect of glucose and basic fibroblast growth factor. Biol Reprod 2005;73:1147-1156.

23 Mochizuki H, Ohnuki Y, Kurosawa H: Effect of glucose concentration during embryoid body (EB) formation from mouse embryonic stem cells on EB growth and cell differentiation. J Biosci Bioeng 2011;111:92-97.

24 Habara-Ohkubo A: Differentiation of beating cardiac muscle cells from a derivative of P19 embryonal carcinoma cells. Cell Struct Funct 1996;21:101-110.

25 Dehne T, Adam X, Materne EM, Reimann MC, Kruger JP, Van Linthout S, Tschope C, Haag M, Sittinger M, Ringe J: A P19 and P19CL6 cell-based complementary approach to determine paracrine effects in cardiac tissue engineering. Cells Tissues Organs 2014;199:24-36.

26 Skerjanc IS: Cardiac and skeletal muscle development in P19 embryonal carcinoma cells. Trends Cardiovasc Med 1999;9:139-143.

27 Mueller I, Kobayashi R, Nakajima T, Ishii M, Ogawa K: Effective and steady differentiation of a clonal derivative of P19CL6 embryonal carcinoma cell line into beating cardiomyocytes. J Biomed Biotechnol 2010;2010:380561.

28 Ohtsu Y, Johkura K, Ito K, Akashima T, Asanuma K, Ogiwara N, Oka T, Komuro I, Sasaki K, Amano J: Stimulation of P19CL6 with multiple reagents induces pulsating particles in vivo. Curr Med Res Opin 2005;21:795-803.

29 Hannes T, Wolff M, Doss MX, Pfannkuche K, Haustein M, Muller-Ehmsen J, Sachinidis A, Hescheler J, Khalil M, Halbach M: Electrophysiological characteristics of embryonic stem cell-derived cardiomyocytes are cell line-dependent. Cell Physiol Biochem 2015;35:305-314.

30 Ding L, Liang X, Zhu D, Lou Y: Peroxisome proliferator-activated receptor alpha is involved in cardiomyocyte differentiation of murine embryonic stem cells in vitro. Cell Biol Int 2007;31:1002-1009.

31 Lai L, Wang M, Martin OJ, Leone TC, Vega RB, Han X, Kelly DP: A role for peroxisome proliferatoractivated receptor gamma coactivator 1 (PGC-1) in the regulation of cardiac mitochondrial phospholipid biosynthesis. J Biol Chem 2014;289:2250-2259.

32 Yu BC, Chang CK, Ou HY, Cheng KC, Cheng JT: Decrease of peroxisome proliferator-activated receptor delta expression in cardiomyopathy of streptozotocin-induced diabetic rats. Cardiovasc Res 2008;80:78-87.

33 Vega-Naredo I, Loureiro R, Mesquita KA, Barbosa IA, Tavares LC, Branco AF, Erickson JR, Holy J, Perkins EL, Carvalho RA, Oliveira PJ: Mitochondrial metabolism directs stemness and differentiation in P19 embryonal carcinoma stem cells. Cell Death Differ 2014;21:1560-1574.

34 Gao CL, Zhu C, Zhao YP, Chen XH, Ji CB, Zhang CM, Zhu JG, Xia ZK, Tong ML, Guo XR: Mitochondrial dysfunction is induced by high levels of glucose and free fatty acids in 3T3-L1 adipocytes. Mol Cell Endocrinol 2010;320:25-33.

35 Czubryt MP, McAnally J, Fishman GI, Olson EN: Regulation of peroxisome proliferator-activated receptor gamma coactivator 1 alpha (PGC-1 alpha) and mitochondrial function by MEF2 and HDAC5. Proc Natl Acad Sci U S A 2003;100:1711-1716.

36 Daitoku H, Yamagata K, Matsuzaki H, Hatta M, Fukamizu A: Regulation of PGC-1 promoter activity by protein kinase B and the forkhead transcription factor FKHR. Diabetes 2003;52:642-649.

37 Irrcher I, Ljubicic V, Kirwan AF, Hood DA: AMP-activated protein kinase-regulated activation of the PGC1alpha promoter in skeletal muscle cells. PLoS One 2008;3:e3614. 


\section{Cellular Physiology Cell Physiol Biochem 2016;38:2041-2052 \begin{tabular}{c|c|c|} 
DOI: 10.1159/000445563 & $\begin{array}{l}\text { O 2016 The Author(s). Published by S. Karger AG, Basel } \\
\text { wwww.karger.com/cpb }\end{array}$ \\
and Biochemistry & Published online: May 11, 2016 &
\end{tabular}}

Li et al.: Development, Cardiomyogenesis, Differentiation

38 Kobayashi S, Mao K, Zheng H, Wang X, Patterson C, O'Connell TD, Liang Q: Diminished GATA4 protein levels contribute to hyperglycemia-induced cardiomyocyte injury. J Biol Chem 2007;282:21945-21952.

39 Ku PM, Chen LJ, Liang JR, Cheng KC, Li YX, Cheng JT: Molecular role of GATA binding protein 4 (GATA-4) in hyperglycemia-induced reduction of cardiac contractility. Cardiovasc Diabetol 2011;10:57.

40 Grepin C, Nemer G, Nemer M: Enhanced cardiogenesis in embryonic stem cells overexpressing the GATA-4 transcription factor. Development 1997;124:2387-2395.

41 Hu DL, Chen FK, Liu YQ Sheng YH, Yang R, Kong XQ, Cao KJ, Gu HT, Qian LM: GATA-4 promotes the differentiation of P19 cells into cardiac myocytes. Int J Mol Med 2010;26:365-372.

42 Jamali M, Rogerson PJ, Wilton S, Skerjanc IS: Nkx2-5 activity is essential for cardiomyogenesis. J Biol Chem 2001;276:42252-42258.

43 Cleaver OB, Patterson KD, Krieg PA: Overexpression of the tinman-related genes XNkx-2.5 and XNkx-2.3 in Xenopus embryos results in myocardial hyperplasia. Development 1996;122:3549-3556.

44 Jiang Y, Drysdale TA, Evans T: A role for GATA-4/5/6 in the regulation of Nkx2.5 expression with implications for patterning of the precardiac field. Dev Biol 1999;216:57-71.

45 Lien CL, Wu C, Mercer B, Webb R, Richardson JA, Olson EN: Control of early cardiac-specific transcription of Nkx2-5 by a GATA-dependent enhancer. Development 1999;126:75-84.

46 Searcy RD, Vincent EB, Liberatore CM, Yutzey KE: A GATA-dependent nkx-2.5 regulatory element activates early cardiac gene expression in transgenic mice. Development 1998;125:4461-4470.

47 Tanaka M, Chen Z, Bartunkova S, Yamasaki N, Izumo S: The cardiac homeobox gene Csx/Nkx2.5 lies genetically upstream of multiple genes essential for heart development. Development 1999;126:12691280.

48 Durocher D, Charron F, Warren R, Schwartz RJ, Nemer M: The cardiac transcription factors Nkx2-5 and GATA-4 are mutual cofactors. EMBO J 1997;16:5687-5696.

49 Sepulveda JL, Belaguli N, Nigam V, Chen CY, Nemer M, Schwartz RJ: GATA-4 and Nkx-2.5 coactivate Nkx-2 DNA binding targets: role for regulating early cardiac gene expression. Mol Cell Biol 1998;18:3405-3415.

50 Shiojima I, Komuro I, Oka T, Hiroi Y, Mizuno T, Takimoto E, Monzen K, Aikawa R, Akazawa H, Yamazaki T, Kudoh S, Yazaki Y: Context-dependent transcriptional cooperation mediated by cardiac transcription factors Csx/Nkx-2.5 and GATA-4. J Biol Chem 1999;274:8231-8239. 